\title{
Educação Básica e COVID-19: desafios, estratégias e lições dos professores em tempos de distanciamento social
}

\author{
Basic Education and COVID-19: challenges, strategies and lessons for teachers in times of social
}

distance

Educación Básica y COVID-19: desafíos, estrategias y lecciones de los docentes en tiempos de desapego social

Recebido: 29/10/2021 | Revisado: 06/11/2021 | Aceito: 14/11/2021 | Publicado: 23/11/2021

Grice Anne dos Santos Vaz
ORCID: https://orcid.org/0000-0002-6031-316X
Instituto Federal de Educação, Ciência e Tecnologia de Minas Gerais, Brasil
E-mail: griceannevaz@hotmail.com
Edson de Jesus Santos
ORCID: https://orcid.org/0000-0003-4671-1919
E-mail: hedsonssantos@gmail.com
Cláudio Alves Pereira
Instituto Federal de Educação, Ciência e Tecnologia de Mina Gerais, Brasil
ORCID: https://orcid.org/0000-0002-4829-6272
E-mail: claudio.pereira@ifmg.edu.br

\section{Resumo}

Mesmo sendo conhecidos os problemas da educação no Brasil, a pandemia causada pela Covid-19 aflorou discussões de diversos âmbitos e intensas mobilizações para continuidade do processo educativo. O presente estudo trata-se de uma pesquisa qualitativa que tem como objetivo analisar e apresentar os dados obtidos por meio de pesquisa feita com professores com o intuito de mapear as estratégias, os desafios e as lições do ensino remoto experimentado neste período de necessário distanciamento social. Para coleta de dados, utilizou-se um questionário eletrônico que contou com a participação de Professores em exercício em instituições de ensino públicas e privadas de várias regiões brasileiras. Utilizou-se o método de amostragem não probabilística denominado Bola de Neve Virtual (ou amostra por rede), que consistiu no envio do questionário por meio de um link, por e-mail e WhatsApp, contendo as questões, o Termo de Consentimento Livre e Esclarecido- TCLE virtual e o pedido de compartilhamento do link com a rede de contatos daquele participante. $\mathrm{O}$ estudo demonstrou que, embora existam diferentes realidades de atuação e alguns casos de sucesso, houve pontos consensuados como sendo comprometedores à prática pedagógica e ao processo de aprendizagem, como as dificuldades de acesso a recursos tecnológicos e internet por parte dos alunos, o não desenvolvimento da autonomia para aprendizagem, a dificuldade de acompanhamento dos pais/responsáveis, a excesso de atividades tanto dos educadores como dos pais, o conteudismo do sistema escolar, e os efeitos negativos na saúde mental de todos envolvidos no sistema.

Palavras-chave: Ensino a distância; Formação continuada do professor; Processo de ensino-aprendizagem; Prática pedagógica.

\begin{abstract}
Even though the problems of education in Brazil are known, the pandemic caused by Covid-19 has surfaced discussions in different areas and intense mobilizations for the continuity of the educational process. The present study is a qualitative research that aims to analyze and present data obtained through research carried out with teachers in order to map the strategies, challenges and lessons of remote education experienced in this period of necessary social distancing. For data collection, an electronic questionnaire was used, with the participation of professors working in public and private educational institutions in several Brazilian regions. The non-probabilistic sampling method called Virtual Snowball (or sample by network) was used, which consisted of sending the questionnaire through a link, by email and WhatsApp, containing the questions, the Informed Consent Form and Clarified - Virtual IC and the request to share the link with that participant's network of contacts. The study showed that, although there are different realities of action and some cases of success, there were points consensual as compromising the pedagogical practice and the learning process, such as difficulties in accessing technological resources and the internet for students, non-development autonomy for learning, the difficulty of monitoring parents/guardians, excessive activities by both educators and parents, the content of the school system, and the negative effects on the mental health of everyone involved in the system.
\end{abstract}

Keywords: Distance learning; Continuing teacher education; Teaching-learning process; Pedagogical practice. 


\begin{abstract}
Resumen
Si bien se conocen los problemas de la educación en Brasil, la pandemia provocada por el Covid-19 generó discusiones desde diferentes áreas e intensas movilizaciones por la continuidad del proceso educativo. Este estudio es una investigación cualitativa que tiene como objetivo analizar y presentar los datos obtenidos a través de investigaciones realizadas con docentes con el fin de mapear las estrategias, desafíos y lecciones de la educación a distancia vividas en este período de necesario desapego social. Para la recolección de datos se utilizó un cuestionario electrónico, con la participación de profesores en la práctica en instituciones educativas públicas y privadas en varias regiones brasileñas. Se utilizó el método de muestreo no probabilístico denominado Bola de Nieve Virtual (o muestra por red), que consistió en enviar el cuestionario a través de un enlace, por correo electrónico y WhatsApp, conteniendo las preguntas, el Formulario de Consentimiento Libre e Informado y Aclarado - TCLE virtual y la solicitud de compartir el enlace con la red de contactos de ese participante. El estudio demostró que, si bien existen diferentes realidades de desempeño y algunos casos de éxito, existen puntos consensuados como comprometedores para la práctica pedagógica y el proceso de aprendizaje, como las dificultades de acceso a los recursos tecnológicos e internet por parte de los estudiantes, la autonomía no desarrollada para el aprendizaje, la dificultad para acompañar a los padres / tutores, la exceso de actividades tanto de los educadores como de los padres, el contenido del sistema escolar y los efectos negativos en la salud mental de todos los involucrados en el sistema.
\end{abstract}

Palabras clave: La educación a distancia; Formación continua del profesorado; Proceso de enseñanza-aprendizaje; Práctica pedagógica.

\title{
1. Introdução
}

As discussões sobre a qualidade da educação não são novidade, mas os impactos da pandemia provocados pelo coronavírus SARS-CoV-2 no sistema educacional tornaram ainda mais evidentes os nossos problemas e disparidades, trazendo novas discussões sobre a Educação no Brasil.

Com o avanço da pandemia no ano de 2020, a principal recomendação emitida pelos comitês científicos e pela Organização Mundial da Saúde (OMS) foi para o necessário distanciamento social entre os indivíduos, visando diminuir os índices de transmissibilidade do vírus e, consequentemente, diminuir os casos de contaminação. Contudo, esta medida trouxe reflexos em diversas áreas e, dentre elas, para a Educação. Na busca de soluções, o Ministério da Educação (MEC) possibilitou às instituições de ensino brasileiras, por meio de normatizações, a oportunidade de ofertar aulas remotas aos estudantes (Brasil, 2020); especificamente para a Educação Básica, destaca-se a Nota de Esclarecimento do Conselho Nacional de Educação (CNE) publicada em 18 de março de 2020, primeiro documento a nortear as escolas de educação básica a como deveriam proceder. Nesse contexto, surgiu uma grande mobilização das instituições, professores, alunos e famílias para se adaptarem, em pouco tempo, a essa modalidade que passou a ser denominada de Ensino Remoto Emergencial (ERE) ${ }^{1}$.

Os professores são a parte mais aparente desse processo, mas não são os únicos. Contudo, uma elevada carga de trabalho foi depositada nestes profissionais e, recebendo ou não o suporte institucional e das famílias, tiveram que se adaptar compulsoriamente para darem continuidade ao ensino nas diferentes realidades em que atuavam. As questões de saúde-doença relacionadas à docência já se apresentavam em maior ou menor grau na vida de educadores, ocasionando efeitos denominados como "mal-estar docente" (Esteve, 1999). No entanto, com a pandemia, além dos impactos à saúde mental desses profissionais pelo temor de ser infectado pelo coronavírus, uma sobrecarga emocional diretamente ligada às novas formas da prática pedagógica, à identidade docente e às novas demandas, têm refletido nos índices de adoecimento entre os profissionais da educação (Hashizume, 2020; Pereira, Santos \& Manenti, 2020).

Com a pandemia, as modalidades de ensino que não são exclusivamente presenciais ganharam maior destaque nos planejamentos pedagógicos, nas reuniões de equipes gestoras e de coordenação de cursos, além de seus conceitos e terminologias próprios serem largamente apresentadas na mídia. Agora, entraram com vigor no campo das discussões o Ensino Híbrido e o ERE, que embora em alguns pontos se assemelhem ao já difundido Ensino a distância (EaD), não são sinônimos.

${ }^{1}$ Utilizaremos esse termo de maneira genérica. Embora o termo não tenha sido comum a todas as instituições brasileiras, foi um dos termos mais utilizados para identificar essa reorganização do ensino presencial durante a pandemia. 
Nesse sentido, Bacich (2020) acredita que o Ensino Híbrido esteja inserido no rol de metodologias ativas em que há uma concepção de aluno protagonista, requerendo um estudo um pouco mais aprofundado e uma reflexão sobre o papel das tecnologias digitais nesse processo. Para Moran (2017), a combinação da aprendizagem ativa e hibrida com tecnologias móveis é poderosa para desenhar formas interessantes de ensinar e aprender (Moran, 2017, p. 23).

Ganham especial destaque as discussões sobre o ERE e a necessidade deste modelo se distanciar da EaD e do Ensino Híbrido. No contexto dessa pandemia, o ERE é uma mudança curricular temporária e alternativa devido às circunstâncias exigidas para o seu enfrentamento. Ao contrário das experiências planejadas desde o início e projetadas para serem online, o Ensino Remoto de Emergência (ERT) é uma mudança temporária para um modo de ensino alternativo devido a circunstâncias de crise (Hodges, Trust, Moore, Bond \& Lockee, 2020, p. 6). Os autores ainda explicam que o ERE difere da modalidade EaD, pois esta conta com recursos próprios e uma equipe multiprofissional preparada para ofertar os conteúdos e atividades pedagógicas, por meio de diferentes mídias em plataformas on-line.

Nesse contexto, esse estudo apresentará os dados conseguidos junto a professores lotados em instituições de ensino públicas e privadas de várias regiões brasileiras e aponta as estratégias, os desafios e lições do ensino remoto durante a pandemia da Covid-19.

\section{Metodologia}

Para coleta de dados, este estudo utilizou um questionário eletrônico aplicado a professores em exercício em instituições de ensino públicas e privadas no Brasil; o questionário foi do tipo auto-aplicado construído e disponibilizado por meio do Google Forms. Por utilizar o pacote de aplicativo Google Docs, a coleta e o uso de informações ficaram sujeitos à Política de privacidade do Google. A coleta de dados utilizando um questionário virtual foi escolhida, principalmente, por proporcionar a participação de indivíduos de diversas localizações geográficas.

Adotou-se a abordagem qualitativa na apresentação das análises. Segundo Diehl (2006), essa opção demonstra o objetivo de descrever a complexidade que envolve determinado problema, tornando necessário entendê-lo e classificar os processos dinâmicos na ordem em que são vivenciados pelos grupos.

Para coleta e análise dos dados foram construídas sete categorias de análise, sendo elas: (i)Característica e Perfil do participante; (ii) Realidade do Professor; (iii) Capacitação(ões) em EaD; (iv) Política educacional e infraestrutura da instituição; (v) Uso pedagógico de recursos tecnológicos; (vi) Realidade dos alunos; e (vii) Anseios e frustrações. Ao todo, foram elaboradas 17 questões de múltipla escolha, além de uma questão aberta. Especificamente para esta última, o objetivo pretendido foi oportunizar ao participante um espaço para sua livre manifestação, espaço para que este pudesse registrar e socializar os anseios, relatos e outras informações consideradas por ele relevantes e que estivessem relacionadas ao tema do estudo e às suas vivências. A cada instituição que o participante atuava lhe era orientado para que respondesse a um questionário específico para cada uma delas.

Na primeira seção do questionário foi inserido o Termo de Consentimento Livre e Esclarecido- TCLE virtual composto por uma página de esclarecimento sobre a pesquisa, além da solicitação de autorização para o uso dos dados. Este estudo foi aprovado pelo Comitê de Ética em Pesquisa com Seres Humanos da Universidade Federal de Lavras (COEP/UFLA).

Com vistas a identificar possíveis falhas na redação do questionário e buscar assegurar a validade e precisão na coleta de dados, dez professores participaram da fase de pré-teste do questionário. Identificadas as melhorias e correções necessárias, $\mathrm{o}$ instrumento foi atualizado.

Para o envio do questionário, adotou-se o método de amostragem não probabilística proposto por Costa (2018), conhecido como Bola de Neve Virtual. Segundo Sampieri, Collado \& Lucio (2006), este método pode ser entendido como 
processo de amostra por rede. O link de acesso ao questionário foi enviado por e-mail e WhatsApp. Nessa técnica, além dos professores serem convidados a participar da pesquisa, também lhes foi solicitado que compartilhassem o link com seus contatos. Costa (2018) denomina esta forma de encaminhamento do questionário como estratégia viral, sendo uma amostragem não probabilística que, devido à sua natureza, não permitem generalizar os resultados da pesquisa para a população. Dessa forma, esse trabalho buscou contribuir para as discussões sobre o tema, e não a generalização dos dados para a representação de uma região ou tipo de instituição ou nível de ensino.

Para análise e interpretação dos dados foi utilizada a técnica de "análise de conteúdo". Esse método pode ser entendido como um conjunto de técnicas da análise de comunicações visando obter, por procedimentos, sistemáticos e objetivos de descrição do conteúdo das mensagens, indicadores (quantitativos ou não) que permitam a inferência de conhecimentos relativos às condições de produção/recepção (variáveis inferidas) destas mensagens (Bardin, 1977).

\section{Resultados e Discussão}

Considerando que a cada instituição em que o participante atuava foi respondido um questionário, este estudo obteve um total de 210 questionários respondidos e 142 professores participantes da pesquisa. Quanto ao estado brasileiro de localização dos participantes, registra-se participantes em 16 estados do Brasil.

Figura 1. Número de Professores participantes da pesquisa por estado do país.

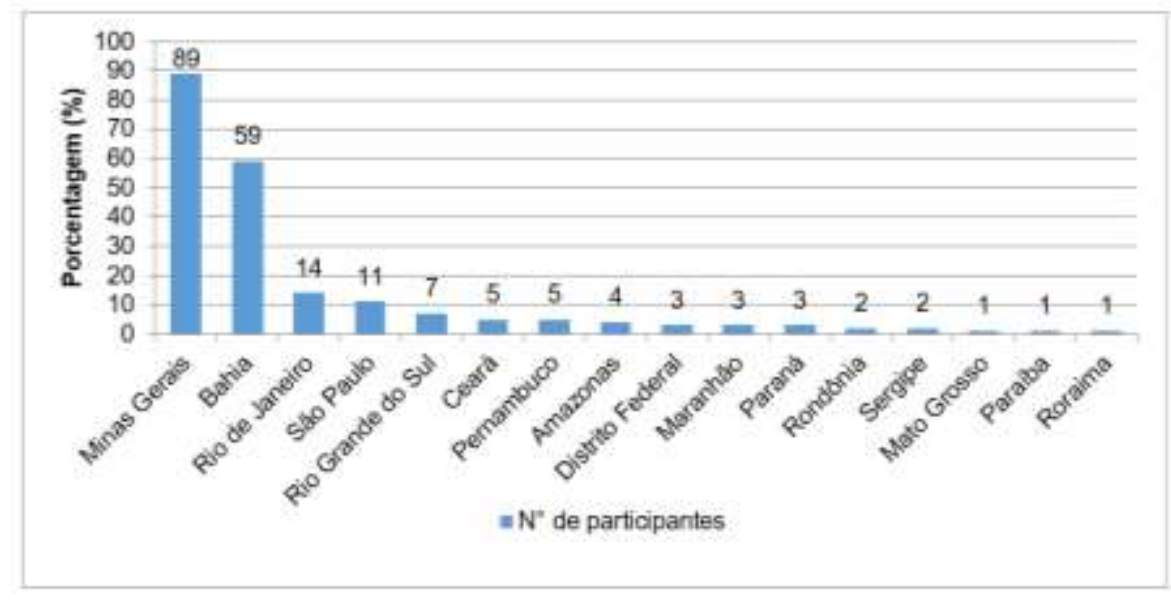

Fonte: Autores (2021).

Conforme gráfico acima, destacam-se Minas Gerais com 89 participantes (42,4\%), Bahia com 59 participantes (28,1\%), Rio de Janeiro com 14 participantes (6,7\%) e São Paulo com 11 participantes (5,25\%). Os demais estados tiveram entre 1 e 7 participantes, representando menos de 5\% do total. Infere-se que a maior porcentagem em Minas Gerais e na Bahia tenha sido obtida por terem sido esses os pontos de partida do link do questionário, tendo assim alcançado maior número pessoas e de compartilhamentos.

A interrupção das aulas presenciais no país iniciou em março de 2020 e, desde então, as instituições de ensino e professores vêm se esforçando na busca de caminhos para a adoção do ERE. Questionados se foi mantida alguma atividade escolar/acadêmica com os alunos no período de março a agosto de 2020 (data de disponibilização do link para a pesquisa), $74,1 \%$ informaram que "Sim", ainda que parcialmente. 
Figura 2. Continuidade do ensino e realização de atividades remotas.

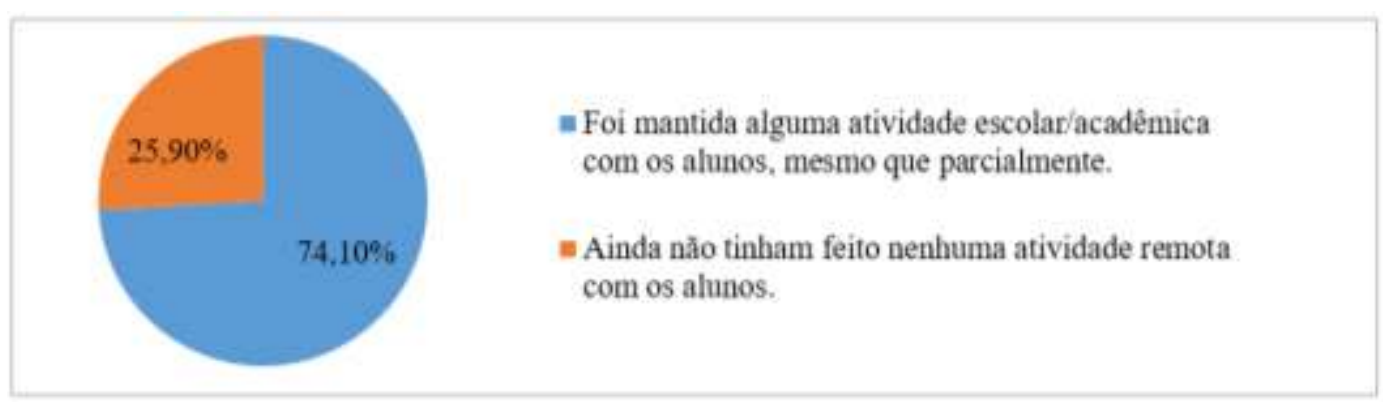

Fonte: Autores (2021).

O resultado exposto acima não diferiu da tendência apresentada em pesquisas nacionais realizadas no mesmo período, a exemplo do informativo sobre a Inclusão escolar em tempos de pandemia feito pelo Departamento de Pesquisas Educacionais da Fundação Carlos Chagas (DPE/FCC, 2020) na Educação Básica que mostrou que, até julho de 2020, apenas 7,3\% dos respondentes relataram ainda não terem se organizado para o ensino remoto (Fundação Carlos Chagas, 2020).

No caso dos participantes que responderam ainda não terem feito nenhuma atividade, considera-se que, diante das incertezas do cenário educacional brasileiro, muitas estratégias para descobertas da melhor forma de utilizar o ERE foram utilizadas. Assim, é possível que, no momento da coleta de dados para esta pesquisa, os professores (e suas instituições de ensino) ainda poderiam estar em fase de planejamento das atividades. Além disso, "algumas instituições suspenderam as aulas e concederam férias aos estudantes e aos profissionais de educação, enquanto outras se adaptaram ao regime de educação remota" (Unesco, 2020). Segundo o Relatório realizado pelo Grupo de Estudos sobre Política Educacional e Trabalho Docente (GESTRADO) da Universidade Federal de Minas Gerais (UFMG), 3,2\% das escolas particulares suspenderam as atividades, enquanto nas públicas esse índice foi de 16\% (Gestrado/Ufmg, 2020).

Esse estudo contemplou professores que atuam em diferentes realidades. Como apresentado na Figura 3, do total de 142 participantes, 42,25\% atuavam simultaneamente em mais de um nível de ensino; 9,6\% atuavam apenas no Ensino Infantil; 11,27\% apenas no Ensino Fundamental; 11,97\% apenas no Ensino Médio; 7,04\% exerciam a docência apenas no Ensino Técnico/Profissionalizante e 17,61\% apenas no Ensino Superior. 
Figura 3. Contexto de atuação dos participantes da pesquisa.

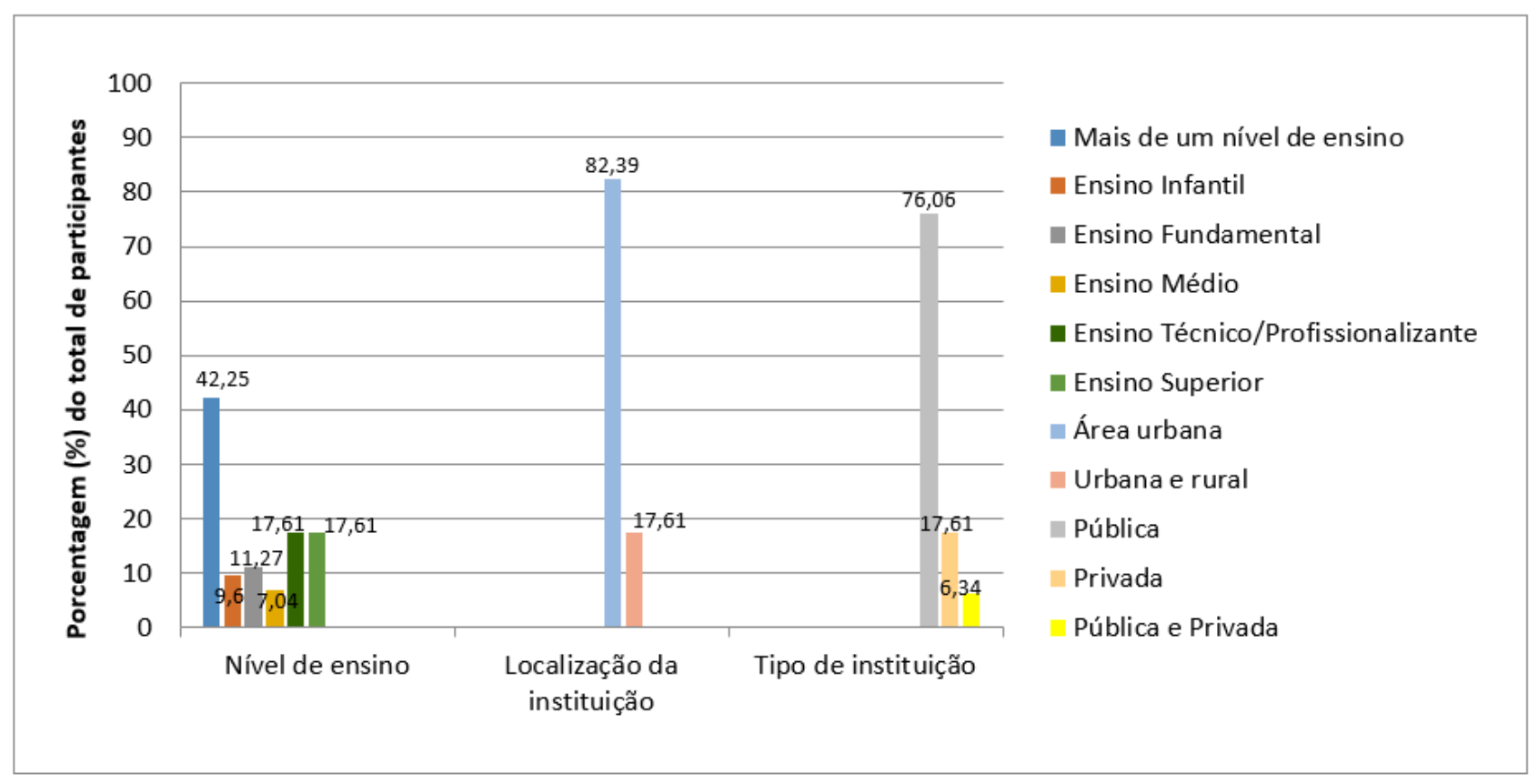

Fonte: Autores (2021).

Quanto à área de localização e tipo de instituições onde atuavam, 82,39\% dos participantes trabalhavam em instituições localizadas em área urbana. Ainda foi possível identificar que 76,06\% dos participantes lecionavam apenas em escolas públicas, 17,61\% apenas em instituições privadas e 6,34\% lecionavam nos dois tipos de estabelecimentos de ensino, simultaneamente.

Pesquisas recentes mostraram que o impacto da pandemia tornou ainda mais evidente a disparidade na educação (Cavalcante, Komatsu \& Menezes Filho, 2020; Kubota, 2020). Diante desse contexto, diferentes estratégias foram necessárias para que os profissionais da educação pudessem ter acesso aos alunos e às suas famílias.

Independentemente de ser ofertada na forma síncrona ou assíncrona, para a realização das atividades pedagógicas, são necessários estrutura e recursos tecnológicos nos ambientes onde professores e alunos passaram a desenvolver as suas práticas de ensino e aprendizagem. Questionados se a instituição havia disponibilizado alguma plataforma, material específico ou se havia realizado algum projeto ou programa para continuidade das atividades escolares nesse período da pandemia, 26,24\% (37 participantes) afirmaram que suas instituições já disponibilizavam recursos antes da pandemia e estes foram mantidos. Para 12,66\% (18 participantes), suas instituições de ensino passaram a disponibilizar a partir do cenário pandêmico; outros 42,98\% (61 participantes) disseram que suas instituições de ensino não haviam disponibilizado nenhum destes recursos até aquele momento (agosto/2020). Acrescenta-se o dado de que 18,1\% (26 participantes) afirmaram que o calendário letivo da(s) instituição (ões) em que trabalhavam havia sido suspenso. A Figura 4 apresenta estes dados. 
Figura 4. Disponibilização de materiais/recursos/ instrumentos pela instituição durante a pandemia.

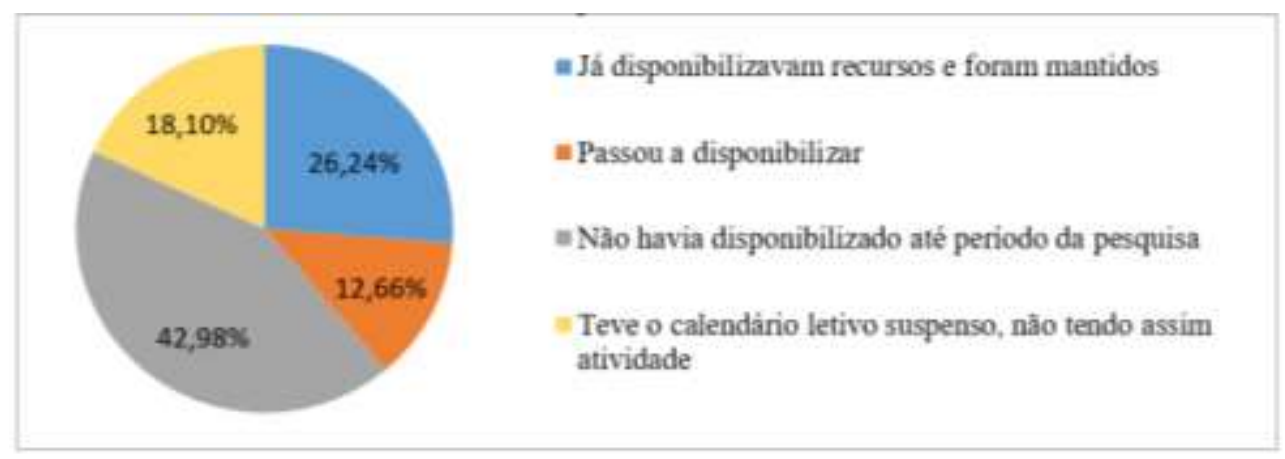

Fonte: Autores (2021).

Conforme Figura 2, a maioria dos participantes $(74,1 \%)$ respondeu ter mantido algum tipo de atividade escolar/acadêmica com os alunos. Pela Figura 4, observa-se que 42,98\% responderam que ainda não havia sido disponibilizado por parte da instituição de ensino algum recurso/material para manutenção das atividades. Assim, pode-se inferir que, mesmo sem apoio institucional, muitos professores buscaram meios próprios para que não fosse completamente interrompido o processo de ensino e aprendizagem dos alunos.

Conforme Valle e Marcom (2020), a crise instaurada pela Covid-19 produziu nas escolas um cenário de muitas mudanças. Para esses autores "a pandemia traz a lume outras características que se vinculam ao novo perfil necessário ao ser professor neste novo tempo" (Valle \& Marcom, 2020, p.146). Para tanto, se fez necessária preparação desses profissionais para esse novo modelo de ensino.

Quanto à capacitação para se trabalhar com ferramentas antes específicas à EaD e para o uso de recursos tecnológicos, 78,1\% (111 participantes) responderam já ter realizado curso(s) a distância e não terem dificuldades na utilização das ferramentas digitais. Para uma parcela de 11,9\% (17 participantes), apesar de já terem realizado curso(s) a distância, disseram ter dificuldades na utilização das ferramentas digitais; outros 13 participantes $(9,05 \%)$ afirmaram nunca terem realizado nenhum curso nessa modalidade ou com esse tema, mas consideram não ter dificuldades no uso de ferramentas digitais. Por fim, $0,95 \%$ ( 1 participante) informou nunca ter realizado cursos dessa natureza por ter dificuldade com as ferramentas digitais e/ou faltar infraestrutura necessária. A Figura 5 apresenta um gráfico com estes dados.

Figura 5. Formação na modalidade EaD e facilidade/dificuldade no uso de recursos tecnológicos.

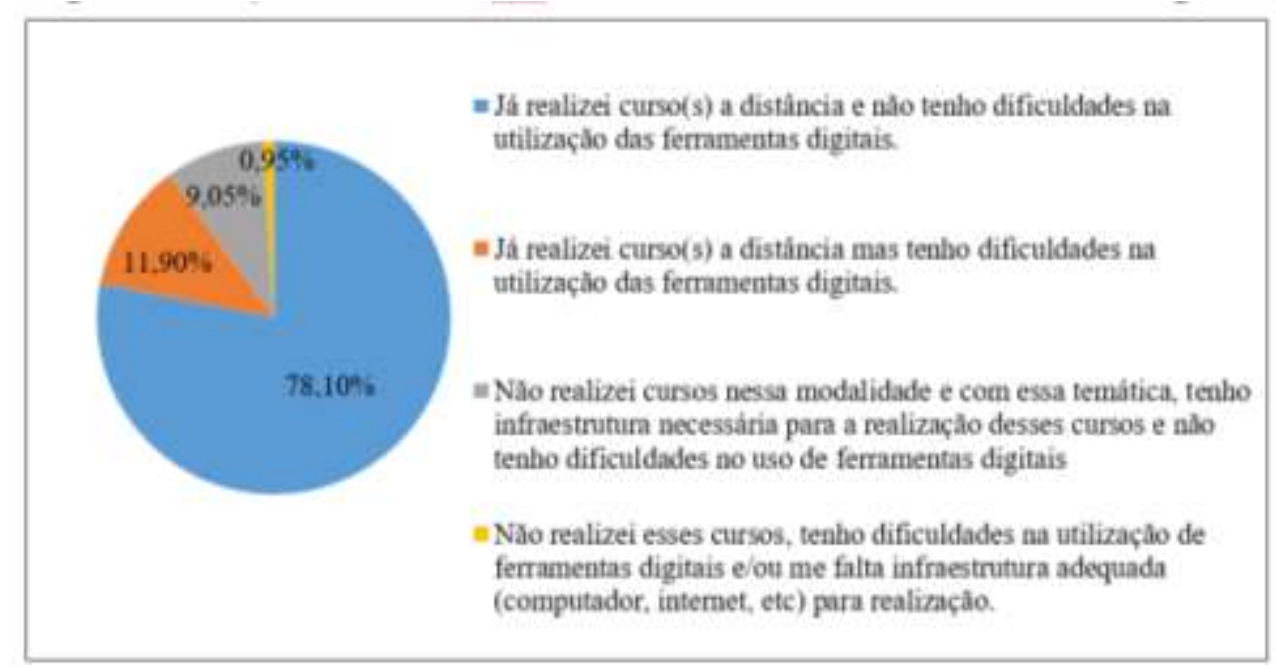

Fonte: Autores (2021). 
A falta de hábito com recursos tecnológicos é também um desafio a ser considerado pelos professores durante o ERE. As pesquisas do GESTRADO/UFMG (2020) relacionaram a falta de experiência no uso das tecnologias à inexpressiva disseminação dessas ferramentas no cotidiano escolar dos professores, faltando-lhes capacitação para esse trabalho. Partindo desse pressuposto, os dados obtidos dos participantes em nosso estudo quanto a familiarização de ferramentas para o trabalho no meio digital podem ser relacionados às pesquisas daquele grupo de maneira a entendermos esse fenômeno.

Pela Figura 5, observa-se que grande parte dos respondentes disse já ter realizado alguma capacitação $(78,1 \%)$ na modalidade EaD e outros 9,05\% disseram não ter dificuldades no uso desses recursos. Desse modo, observa-se que os desafios trazidos pelos participantes da pesquisa não estão relacionados à condição de estudantes em cursos ofertados via EaD ou ainda na falta de preparo/manuseio de suportes tecnológicos ainda na condição de aprendiz. O que se evidencia é a falta de formação para atuar como professor em um formato diferente do ensino presencial, à dificuldade de utilizar os recursos tecnológicos para a preparação de aulas. Assim, deduz-se que há um distanciamento entre ser aluno da EaD e ser professor do ERE, o que reforça a necessidade de uma formação específica para exercer a docência em um ambiente com outras particularidades, o virtual (agravado pelas questões de tempo de adaptação e estrutura necessária para a preparação de aulas no novo formato).

Historicamente, os cursos de licenciatura têm preparado professores para o ensino presencial. Então, mesmo com habilidades para o manuseio de tecnologias digitais conseguidas em outros momentos de formação, muitos participantes deste estudo disseram não possuir, antes da pandemia, preparo didático e experiência para o ERE, bem como estrutura em suas casas para lecionarem nesse formato. Conforme Barros, Coelho, Camargos, Lélis \& Kloster Júnior (2020), neste período emergencial, "torna-se ainda mais difícil uma formação continuada de forma obrigatória, pois demandaria mais do tempo daquele que no momento improvisa suas videoaulas, corrige os trabalhos e faz seu material didático na mesma esfera do lar, cuidando da casa e dos filhos" (p. 53).

Dos professores que responderam estar desenvolvendo algum tipo de atividade pedagógica com os seus alunos, mais da metade deles fazem uso de algum recurso tecnológico para a realização destas atividades, sendo a forma mais utilizada para interação as estratégias de formação de grupos nos aplicativos WhatsApp, Telegram ou Facebook (utilizadas por 74,65\% dos participantes). A Tabela 1 apresenta dados mais detalhados sobre essas estratégias.

Tabela 1. Métodos utilizados pelos respondentes para interação e atividades com os alunos.

\begin{tabular}{|c|c|c|}
\hline Tipo de atividade remota ou recurso utilizado & $\begin{array}{c}\mathbf{N}^{\circ} \text { de respondentes que utilizam esse } \\
\text { meio/recurso }\end{array}$ & $\begin{array}{l}\text { Porcentagem }(\%) \text { em relação } \\
\text { ao total }\end{array}$ \\
\hline $\begin{array}{l}\text { Criado grupo de WhatsApp, Telegram ou Facebook para envio de } \\
\text { atividades, discussão, apoio na resolução das atividades sobre os conteúdos, } \\
\text { e/ou envio de atividades por } e \text {-mail. }\end{array}$ & 106 & 74,65 \\
\hline Disponibilizados aos alunos os conteúdos de estudo em formato PDF. & 102 & 71,83 \\
\hline $\begin{array}{l}\text { Sugeridos para os alunos links e sites de videoaula de conteúdo específico, } \\
\text { arquivos online, filmes. }\end{array}$ & 99 & 69,72 \\
\hline $\begin{array}{l}\text { Desenvolvidas atividades em plataforma digital para o trabalho online em } \\
\text { ambiente virtual/salas virtuais para esclarecimento de dúvidas/fóruns. }\end{array}$ & 76 & 53,52 \\
\hline Organizadas reuniões virtuais/lives entre o/a professor/a e os alunos. & 67 & 47,18 \\
\hline Produzidos vídeos das minhas próprias aulas, gravadas na minha casa. & 65 & 45,77 \\
\hline $\begin{array}{l}\text { Foi (está sendo) entregue ao aluno (ou a seu responsável) o material } \\
\text { impresso para estudo em casa. }\end{array}$ & 57 & 40,14 \\
\hline $\begin{array}{l}\text { Foi (está sendo) desenvolvido um aplicativo para manter contato com os } \\
\text { alunos. }\end{array}$ & 39 & 27,46 \\
\hline $\begin{array}{l}\text { Transmitidos conteúdos pela TV (eu não participei da produção destes } \\
\text { vídeos). }\end{array}$ & 18 & 12,68 \\
\hline
\end{tabular}

Fonte: Autores (2021). 
Esses resultados corroboram com a ideia do GESTRADO/UFMG (2020) de que a disseminação das ferramentas está relacionada à capacitação docente, sendo as dificuldades ainda maiores quando os docentes não recebem nenhuma formação para a utilização de ferramentas tecnológicas necessárias ao desenvolvimento das atividades remotas.

De acordo com a Pesquisa Nacional por Amostra de Domicílios Contínua - Tecnologia da Informação e Comunicação (PNAD Contínua TIC, 2018) realizada pelo Instituto Brasileiro de Geografia e Estatística (IBGE ${ }^{2}$ ), o telefone celular é o principal meio de acesso à rede móvel no país, usados por quase todos os brasileiros. Considerando a acessibilidade e a disponibilidade dos recursos em seus domicílios para utilização no planejamento e execução de suas aulas e/ou atividades remotas, observou-se que os equipamentos mais presentes na rotina dos participantes desse estudo eram, respectivamente o notebook, smartphone, impressora, computador de mesa (desktop) e tablet. Embora em quantidade menor, foram identificados a televisão, o rádio e outros não tecnológicos, porém, com menor expressividade, conforme exposto pela Tabela 2.

Tabela 2. Equipamentos disponíveis em casa e utilizados para o planejamento e execução de suas aulas e/ou atividades.

\begin{tabular}{l|c|c}
\multicolumn{1}{c|}{ Equipamento disponível em casa } & $\begin{array}{c}\mathbf{N}^{\circ} \text { de respondentes que } \\
\text { utilizam }\end{array}$ & $\begin{array}{c}\text { Porcentagem (\%) em relação } \\
\text { ao total }\end{array}$ \\
\hline Notebook & 131 & 92,38 \\
\hline Smartphone (celular com acesso à internet) & 124 & 87,62 \\
\hline Impressora & 78 & 55,24 \\
\hline Computador de mesa & 43 & 30,00 \\
\hline Tablet & 33 & 23,33 \\
\hline $\begin{array}{l}\text { Outros: televisão e formas não tecnológicas, gravador, câmera e tripé, Soft } \\
\text { box (iluminação), Mesa digitalizadora, microfone, iluminação especial, } \\
\text { câmera digital, quadro branco e pincel, caixa de som }\end{array}$ & 6 \\
\hline Nenhum recurso, seja tecnológico ou não tecnológico & 6 & 4,29 \\
\hline
\end{tabular}

Fonte: Autores (2021).

Conforme Barbosa, Viegas e Batista (2020) ao sair da sala de aula física para a virtual, sem ser o habitual e milenar uso dos métodos tradicionais de ensino, se faz necessárias adaptações não instantâneas. Ainda durante o ensino presencial, os profissionais de educação já lidavam com os desafios de organizar práticas pedagógicas capazes de contemplar os diferentes estilos de aprendizagem e garantir a efetividade do processo de aprendizagem dos estudantes. Com a instituição do ERE e as consequentes adaptações em suas práticas, desta vez planejadas para acontecerem unicamente longe da sala de aula, esse desafio do processo de ensino e aprendizagem ficou ainda maior. Neste período, segundo os participantes, os instrumentos de avaliação e registro de aprendizagem das aulas antes utilizados nas atividades presenciais, se mostravam ineficazes nesse novo cenário.

Perguntados sobre a participação dos alunos nas atividades pedagógicas, 48,37\% (68 participantes) informaram que todos ou a maioria dos alunos davam pouca ou nenhuma atenção e retorno às atividades propostas pelo professor e outros $40,22 \%$ (57 participantes) informaram que os alunos correspondiam às atividades propostas e participavam destas. O gráfico exposto na Figura 6 apresenta todos os dados.

${ }^{2}$ Para acessar a pesquisa completa: http://biblioteca.ibge.gov.br/visualizacao/livros/liv101705_informativo.pdf. 
Research, Society and Development, v. 10, n. 15, e157101522485, 2021

(CC BY 4.0) | ISSN 2525-3409 | DOI: http://dx.doi.org/10.33448/rsd-v10i15.22485

Figura 6. Análise da participação e interação dos alunos nas atividades/aulas.

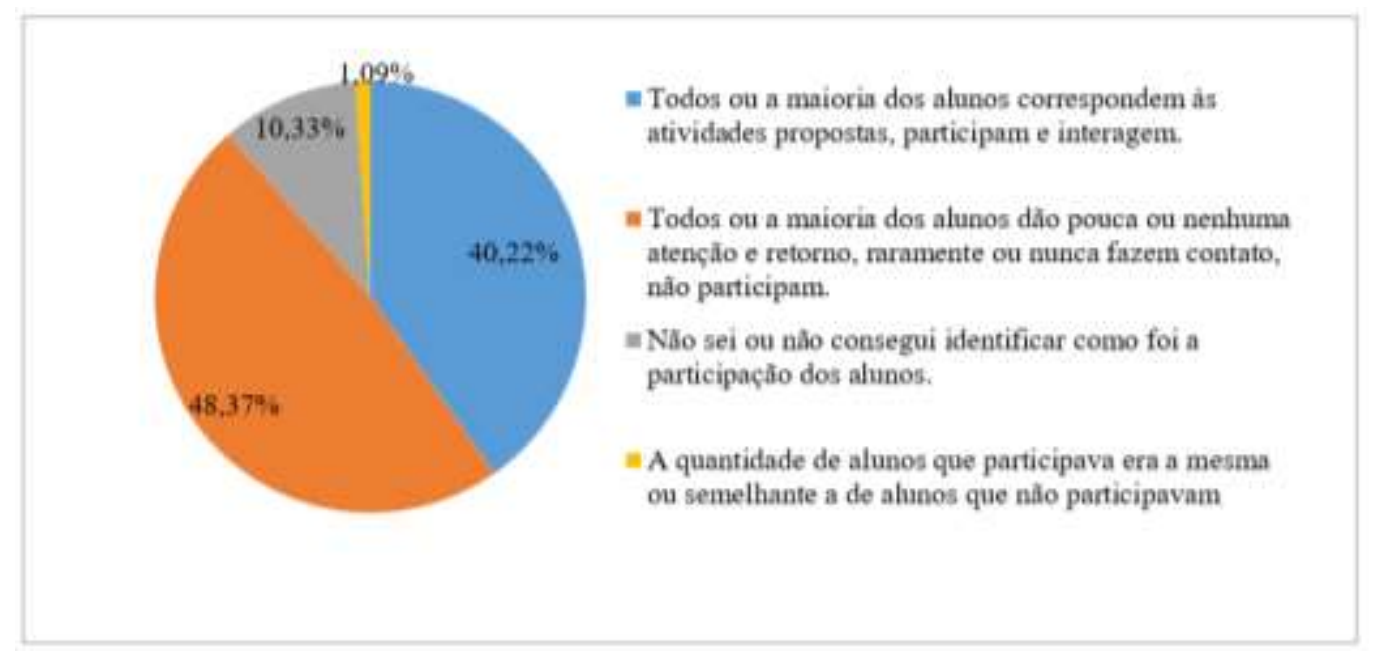

Fonte: Autores (2021).

Conforme se pode observar, quase metade dos alunos não estavam respondendo positivamente às estratégias pedagógicas planejadas pelos professores. Diversos poderiam ser os fatores que influenciavam e/ou afetavam a participação ativa e a interação dos alunos no ERE. Averiguada essa questão junto aos participantes, observou-se uma variedade de fatores que, em suas análises, poderiam estar contribuindo para esse cenário. Embora nesta questão houvessem opções já apresentadas para que o participante apenas assinalasse, havia o campo "Outros" e o participante poderia apresentar livremente o(s) fator(es) que julgava guardar relação com a questão. A Tabela 3, abaixo, agrupa os dados coletados. 
Tabela 3. Motivos informados para a falta de participação, comunicação ou pouca (ou nenhuma) interatividade por parte dos alunos.

\begin{tabular}{|c|c|c|}
\hline Motivos & $\begin{array}{l}\mathbf{N}^{\circ} \text { de respondentes que } \\
\text { informaram esse motivo }\end{array}$ & $\begin{array}{c}\text { Porcentagem (\%) em relação ao } \\
\text { total }\end{array}$ \\
\hline $\begin{array}{l}\text { Falta de interesse, compromisso, hábitos de estudos } \\
\text { autônomos, capacidade de concentração e autodisciplina do } \\
\text { aluno, ou ainda dificuldades de aprendizado. }\end{array}$ & 62 & 43,66 \\
\hline A ausência ou baixa qualidade da rede de internet. & 51 & 35,92 \\
\hline $\begin{array}{l}\text { O aluno não possui equipamento (computador, notebook, } \\
\text { smartphones, tablet ou outro) em casa para acessar as } \\
\text { atividades. }\end{array}$ & 45 & 31,69 \\
\hline Falta de ambiente doméstico adequado para o aprendizado. & 43 & 30,28 \\
\hline $\begin{array}{l}\text { Falta de cobrança, suporte e acompanhamento do(s) pai(s) ou } \\
\text { responsáveis do aluno. }\end{array}$ & 32 & 22,54 \\
\hline $\begin{array}{l}\text { Os recursos utilizados podem ter despertado pouco interesse } \\
\text { dos alunos pelas atividades. }\end{array}$ & 20 & 14,08 \\
\hline $\begin{array}{l}\text { Não sei o motivo que pode ter levado a falta de interação dos } \\
\text { alunos. }\end{array}$ & 6 & 4,23 \\
\hline $\begin{array}{l}\text { Motivos outros: alguns estão cuidando da casa, outros de } \\
\text { parentes que estão doentes e há aqueles que passaram a } \\
\text { sustentar a família. }\end{array}$ & 1 & 0,70 \\
\hline $\begin{array}{l}\text { Motivos outros: Os pais dos meus alunos (infantil) reclamam } \\
\text { não ter tempo ou condições de acompanhar as crianças }\end{array}$ & 1 & 0,70 \\
\hline $\begin{array}{l}\text { Trabalho doméstico, cuidados com filhos e outros parentes, } \\
\text { crises de ansiedade. }\end{array}$ & 1 & 0,70 \\
\hline $\begin{array}{l}\text { As atividades não são obrigatórias. O estudante pode optar em } \\
\text { não participar ou realizar. }\end{array}$ & 1 & 0,70 \\
\hline $\begin{array}{l}\text { Temos muitos alunos cujas famílias vivem em situações de } \\
\text { precariedade e vulnerabilidade, intensificadas no momento } \\
\text { atual. Para muitos deles, com os pais desempregados, o } \\
\text { contato durante a suspensão do calendário não é a maior } \\
\text { prioridade. As atividades propostas são apenas para } \\
\text { engajamento, não foi feita uma substituição das aulas } \\
\text { presenciais pelas remotas. }\end{array}$ & 1 & 0,70 \\
\hline Desânimo pela pandemia & 1 & 0,70 \\
\hline $\begin{array}{l}\text { Atividade sem validade acadêmica devido à suspensão do } \\
\text { calendário }\end{array}$ & 1 & 0,70 \\
\hline $\begin{array}{l}\text { Motivos psicológicos (desânimo, apreensão, incertezas } \\
\text { perante uma situação inédita e pouco otimista); atividades } \\
\text { pouco motivadoras. }\end{array}$ & 1 & 0,70 \\
\hline $\begin{array}{l}\text { Os alunos possuem equipamentos, mas são de baixa qualidade } \\
\text { e/ou não sabem utilizar plataformas diferentes das mais } \\
\text { comuns, como Instagram, Facebook e Whatsapp }\end{array}$ & 1 & 0,70 \\
\hline $\begin{array}{l}\text { Impossibilidade de acompanharem as atividades sozinhos por } \\
\text { se tratarem de pessoas com deficiência intelectual que } \\
\text { necessitam de acompanhamento constante. }\end{array}$ & 1 & 0,70 \\
\hline Ausência de letramento digital & 1 & 0,70 \\
\hline
\end{tabular}

Fonte: Autores (2021).

Chama a atenção o percentual de 43,66\% dos participantes da pesquisa que relacionam o baixo índice de participação a aspectos intrínsecos ao aluno e para os quais o cenário pandêmico dificulta essa aproximação. Também se mostra preocupante (e relaciona-se à essa dificuldade de contatar o estudante e sua família) o percentual de 35,92\% dos participantes que atribuem a baixa participação dos estudantes à ausência ou baixa qualidade da rede de internet em seus domicílios.

Um fator que deve ser considerado para o ERE é que nem sempre o ambiente doméstico é favorável ao estudo e à aprendizagem. Conforme Catanante, Dantas e Campos (2020), de forma ideal, estudar de maneira sistemática exige um espaço adequado, com boa iluminação, ausência de distrações. "Para o Coletivo de Estudos em Marxismo e Educação 
(COLEMARX), o uso dos artefatos tecnológicos não pode ser pensado de modo desvinculado das condições de habitação dos estudantes da educação básica e superior" (Colemarx, 2020, p. 16). Como exemplo, citam famílias que dividem pequeno espaço, não sendo possível em isolamento social assegurar nessas condições a concentração mínima para o estudo do aluno.

Catanante, Dantas \& Campos (2020) acreditam que:

O ambiente residencial possui uma estrutura própria que o difere do ambiente escolar, sendo que este pressupõe toda uma organização para as atividades do ensino, que permite até falar em currículo oculto, ou seja, uma estrutura subjacente, mas que possui implicações educacionais. O ambiente residencial, por sua vez, por mais adequado que seja, não foi criado para ser um ambiente educativo. (Catanante, Dantas \& Campos, 2020, p. 981).

Além disso, um dos grandes pontos discutido para a instituição de aulas remotas é a falta de acesso aos recursos pelos alunos. Segundo o Colemarx (2020):

Mais de $40 \%$ das residências não possuem computador e, entre os que possuem, poucos possuem softwares atualizados e capacidade de armazenamento. E são de uso comum de 3 ou mais pessoas(...) A maior parte do acesso à internet é realizada por meio de celulares, o que não assegura conectividade compatível com as plataformas de $\mathrm{EaD}(. .$.$) A democratização do acesso à internet, por meio de políticas públicas, é, por conseguinte, um imenso desafio$ e deve seguir na agenda das lutas pela democratização da informação, da ciência, da arte e da cultura. (Colemarx, 2020, pp. 16-17).

Contudo, ressaltam que não está em questionamento a relevância das Tecnologias de Informação e Comunicação (TIC) para a vida social e, especificamente, para a educação, mas a democratização do acesso à internet, por meio de políticas públicas como um direito fundamental no século XXI.

\subsection{Inquietações, desafios e lições da pandemia}

Por meio da questão aberta do questionário eletrônico, este estudo pôde conhecer as inquietações, descontentamentos e outros fatores que marcavam, naquele momento (agosto/2020) os participantes deste estudo que atuavam como professores em um cenário de pandemia e de necessário distanciamento social.

Foram destacadas pelos participantes: $(i)$ as dificuldades financeiras das famílias dos alunos; (ii) a falta de acesso aos recursos tecnológicos e à internet; (iii) as dificuldades de adaptação de um ambiente doméstico para um ambiente de estudos para os alunos; (iv) a ausência ou impossibilidade de acompanhamento dos alunos pelos pais; ( $v$ ) a falta de autonomia dos alunos para estudar nessa modalidade remota; (vi) a incerteza da aprendizagem nas atividades realizadas (relacionada à dificuldade de construção de instrumentos avaliativos para essa nova modalidade, respeitando os limites de acessibilidades, inclusive digital, por parte dos alunos) (vii)a falta de recursos, internet de qualidade e condições de trabalho dos próprios professores; (viii) o aumento das atividades na pandemia e a excesso de atividades nos alunos, pais e professores; e (ix) os efeitos da pandemia na saúde física e mental de todos esses envolvidos, em especial do educador.

Quanto ao aspecto financeiro dos pais, foi relatado por alguns participantes que famílias não estavam conseguindo ter o recurso mínimo necessário para uma sobrevivência humana digna, que é a segurança alimentar; outras famílias, segundo relatado, com a chegada da pandemia, tiveram a renda reduzida ou extinta devido ao desemprego, tendo os alunos sido obrigados a buscarem formas para contribuir com a renda familiar. Conforme pontuado nos relatos, tornaram ainda mais evidentes as exclusões na Educação, o abismo social entre as classes sociais, especialmente entre o ensino público e o privado, e entre o ensino ofertado nas áreas urbanas e aquele das escolas rurais, bem como a evasão escolar.

Buscando um diálogo entre os relatos dos entrevistados e os referenciais teóricos selecionados, objetiva-se potencializar a discussão proposta neste estudo. 
Os atuais tempos pandêmicos evidenciaram de uma forma trágica o cenário educacional brasileiro. Já que estudantes de escolas privadas continuam com uma rotina de estudos (focados na lógica utilitária do ENEM e vestibulares) e os estudantes de escolas públicas tem uma rotina precária, ausente ou extremamente questionável de abordagens. (Participante 1: atuante no Ensino Médio em escola pública em área urbana).

Na escola que trabalho que fica na zona rural, a coordenação e equipe gestora resolveram não fazer atividades online devido à falta de acesso dos alunos, pois em algumas localidades não existe bem sinal de celular.(Participante 2: atuante no Ensino Médio em escola pública em área urbana).

Trabalho numa comunidade carente onde poucos tem acesso à internet e muitos não tem comida para pôr à mesa. [...] Uma aluna que participava de um projeto desistiu, porque ela precisa agora ajudar a família dela a achar um jeito de por comida na mesa. Outro aluno também desistiu porque só tinha um computador na casa dele, e ele tinha que compartilhar com o pai, que está trabalhando em home office, e com os irmãos, que também precisam do computador pra estudar.(Participante 3: atuante na Educação Infantil em escola pública em área urbana).

Esta pandemia tem tornado a desigualdade ainda mais evidente na sociedade. Segundo Vieira e Ricci (2020),

Enquanto algumas crianças têm acesso a tecnologias de ponta, possuem acesso ilimitado à internet e recebem em casa o apoio dos pais/responsáveis, tantas outras ficam à margem deste processo, seja pela falta de equipamento tecnológico adequado em casa, seja pelo fato de os responsáveis dedicarem-se a outras preocupações, seja por estes não terem a formação escolar adequada para orientá-los em relação à realização das atividades ou, ainda, por situações de extrema pobreza e vulnerabilidade social. (Vieira \& Ricci, 2020, p. 3).

Conforme os relatos, diante desse contexto de angústia e incertezas, muitos pais não têm condições emocionais, psicológicas e/ou tempo para acompanharem as atividades escolares dos filhos, outros não estão habituados a essa tarefa ou atribuem essa responsabilidade unicamente aos professores. Dos fatores relacionados intrinsecamente aos alunos, foi preocupação trazida por alguns participantes os impactos da pandemia e do distanciamento social na saúde emocional e psicológica desses jovens, ressaltado como obstáculo ao ensino a falta do hábito de rotinas de estudo em casa e a falta de autonomia estudantil para o seu próprio processo de aprendizagem. Quanto à modalidade e nível de ensino, alguns participantes destacaram as dificuldades específicas para os estudantes da Educação de Jovens e Adultos (EJA) e da Educação Infantil.

Em uma das escolas onde trabalho leciono turmas da EJA, eles não tiveram interesse ou condições de acessar as salas de aula virtuais e não realizaram nenhuma atividade. (Participante 4: atuante no Ensino Médio em escola pública em área urbana).

A Educação Infantil são as interações, as vivências, brincadeiras, então, é angustiante pensar em aula remota nesta etapa de ensino. Mas estamos buscando contato com as famílias, mensagens para as crianças através de vídeos, e dicas de brincadeiras e vivências dentro de suas casas. (Participante 5: atuante na Educação Infantil em escola pública em área urbana).

A dificuldade mais notória para aulas remotas é o acesso à internet e, logo em seguida, a disponibilidade de computador pessoal. Contudo, existem questões além, mais sutis: dificuldade de acompanhar atividades no smartphone; existência, qualidade e exclusividade do computador pessoal em casa; ambiente familiar, que pode ser desfavorável (nível de ruído, apoio e orientações para ter disciplina e cumprimento de horários, atividades domésticas etc.); diminuição do "espírito de estudante" e da motivação, no sentido de os colegas, em situação presencial, estimularem naturalmente uns aos outros ao estudo, em uma espécie de "competição" saudável; no mesmo sentido do ponto anterior, diminuição do contato com o mundo acadêmico, como nos intervalos em que se conversa sobre trabalhos, provas, seja com colegas ou com professores e servidores; qualidade da alimentação, principalmente para os mais carentes. Em contrapartida, o ensino à distância com ferramentas digitais pode ser mais favorável que o presencial para os estudantes que já incorporaram o espírito acadêmico, que são mais autodidatas e não estudam apenas por obrigação. Contudo, nota-se que se trata da minoria, o que também parece estar associado a condições favoráveis sobre os aspectos pontuados acima (salvo raras exceções). (Participante 6: atuante no Ensino Técnico e Superior, em instituição pública em área urbana).

Embora seja fundamental para qualquer aluno, a autonomia da aprendizagem é mais abordada em estudos que focam no aluno da EaD, uma vez que nessa modalidade a autonomia estudantil é considerada um pressuposto básico. Historicamente, observa-se que a Educação brasileira tem sido pautada em um sistema de dependência dos alunos por uma tutela, seja pelo 
modelo de Escola compartilhado em casa ou no meio social de sua convivência, o qual pouco estimula e, consequentemente, desenvolve a aprendizagem autônoma e a criação do hábito de investigação autônoma. No atual cenário pandêmico e com a adoção do ERE, essa habilidade tornou-se ainda mais importante para continuidade do processo de ensino-aprendizagem. Para Ruschel, Trevisan e Pereira (2020), quando se fala em adaptação, surgem dois movimentos, sendo um deles relacionado à necessidade do professor de reaprender a planejar, dentro de uma nova realidade, e o outro diz respeito ao aluno que, estando sozinho e isolado, distante do seu grupo social, tem que desenvolver habilidades como autonomia de estudo, domínio de tecnologias e autodisciplina.

A falta de interação dos alunos, a dificuldade para avaliação da aprendizagem, o despreparo do sistema como um todo para realização de atividades remotas, e o foco conteudista das aulas e atividades, principalmente em instituições privadas onde é necessário apresentar andamento do processo escolar e mensurar o quanto se conseguiu em índices de aprendizagem, foram também inquietações trazidas pelos participantes.

O ponto negativo foi concretizar por meio desse momento a convicção de que a escola ainda é a mesma, mesmo com tantas evoluções tecnológicas, o foco ainda é o conteudismo, mas ela não prepara em nada o aluno para desenvolver as competências sócio emocionais, e enfrentar situações simples do cotidiano. (Participante 7: atuante no Ensino Fundamental, em escola pública na área rural).

Tivemos que nos adaptar rapidamente e logo em seguida a escola inventou várias formas de padronizar o conteúdo, além de tabelas e planilhas com visão geral de conteúdos como forma de provar aos pais que o trabalho da escola tem continuado. (Participante 8: atuante na Educação Infantil, em escola privada na área urbana).

Neste contexto pandêmico, a adaptação para a modalidade remota num curto período de tempo torna-se desgastante para muitos professores, demandando ainda mais tempo, esforço, dedicação e recursos tecnológicos e didáticos. Conforme Vieira e Ricci (2020), são diferentes tempos, espaços, ambientes de aprendizagem, condições desiguais de suporte e acesso às tecnologias, dentre outras questões que tornam inviáveis tratar os assuntos da mesma forma como se estivessem sendo trabalhados em sala de aula, sem adequações didático-metodológicas.

Durante a pandemia, muitos professores tiveram afetada sua saúde física, mental e psicológica. As causas são diversas, muitas estando relacionadas à instituição onde trabalhavam, família dos alunos, à sociedade, de maneira geral, e à carga excessiva de tarefas profissionais, familiares e domésticas. No que diz respeito ao posicionamento das instituições de ensino durante a pandemia, variadas foram as ações com relação aos profissionais da educação. Registram-se casos de profissionais que tiveram redução ou corte de salário, aumento de trabalho, ou que ainda foram submetidos a situações de ainda maior sofrimento, como cobranças e pressões constantes, exposição pública sofrida em consequência de aulas gravadas e pela imposição da instituição, publicadas em plataforma de compartilhamento aberto que podem visualizadas e comentadas por qualquer pessoa. Essa última medida, além de registros de desrespeito profissional, causa aumento das tarefas profissionais de gravação, edição e outras etapas que demandam muito mais horas de trabalho quando comparadas ao planejamento de uma aula presencial.

Outra situação que se tornou mais comum durante a pandemia foi a comunicação dos alunos e pais nos meios de contato pessoal dos professores. Alguns o fizeram por opção e disseram preferir esse contato mais próximo e constante com os alunos, mas outros tiveram que fazê-lo por expressa determinação da instituição, medida que, segundo os relatos, resultou em prejuízos à privacidade e à salvaguarda de sua vida pessoal.

A escola obrigou nós professores a criarmos grupos no whatsapp com o número pessoal, desrespeitando nossa privacidade e prejudicando nossa sanidade mental por ter que lidar com pais e alunos 24 horas por dia e a falta de educação os acompanham, sem respeitar horário de serviço.(Participante 9: atuante no Ensino Médio, em escola pública na área urbana). 
Sou uma das poucas na escola completamente aberta ao diálogo e sabem que podem até me ligar qualquer dia e horário. Não me sinto sugada por isso. Fico feliz em ser considerada uma amiga exigente [...]. Infelizmente, com turmas superlotadas e baixos salários, o professor não pode geralmente ter esse tipo de vínculo. (Participante 10: atuante no Ensino Fundamental, em escola pública na área urbana).

A experiência foi negativa da minha exposição ser pública e falta de dinheiro para equipamentos e produção pessoal (maquiagem, cabelo) e dos vídeos. (Participante 11: atuante na Educação Infantil, em escola pública na área urbana).

A Secretaria começou a ofertar aulas a distância e o resultado foi o caos total. Problemas de todos os tipos. A transmissão foi para o youtube. Certamente, nem todos os expectadores eram alunos. Mas os comentários no vídeo aula me fizeram ficar muito triste. Era todo tipo de piada depreciativa. (Participante 12: atuante no Ensino Superior, em escola pública na área urbana).

Mesmo nesse cenário de angústias e incertezas na educação e na vida dos educadores, alguns participantes relataram aprendizados e oportunidades. Nesse sentido, dentre as contribuições e oportunidades citadas pelos participantes, destacou-se o aumento da solidariedade entre os profissionais da educação, provocou reflexões e despertou a necessidade de mobilização para tomada de atitudes altruístas, oportunidade para os pais estarem mais próximo aos filhos, melhoria e reorganização do próprio trabalho docente.

Me proporcionou uma reflexão intensa no que diz respeito à minha vida pessoal e profissional...Acredito que sairemos mais humanos e decididos sobre o que realmente importa para as nossas vidas. Neste momento, no papel de educadora, acredito que a orientação aos alunos sobre os riscos do novo vírus,tão quanto como o uso das plataformas de ensino, dando continuidade aos estudos, através de redes sociais,mensagens,ligações...serão de grande valia. (Participante 13: atuante no Ensino Médio, em escola pública na área urbana).

A experiência do isolamento social, é um verdadeiro aprendizado, sendo um desafio para todos, é necessário se reinventar, flexibilizar e reorganizar, uma profunda reflexão sobre a vida. Uma experiência positiva, meu filho tem dislexia, e com o uso da tecnologia durante o isolamento, ele está se adaptando melhor, fazendo a atividade com interesse, está usando diversos aplicativos que facilita na hora dos estudos. (Participante 14: atuante na Educação Infantil, em escola privada na área urbana).

Uma experiência positiva foi eu ter que aprender a trabalhar com as novas tecnologias no âmbito escolar, mesmo me deixando ansiosa e apreensiva. Estes novos recursos estão contribuindo pra minha transformação e evolução humana pois preciso saber o que falar, ter resiliência, calma, paciência e tolerância, pois, com o uso destes recursos online ficamos muitos mais expostos e somos muito mais criticados de forma destrutiva. Selecionar as críticas nesse período é indispensável a nós docente, precisamos aprender a não interiorizar o que não nos reconstrói como cidadãos e professores. (Participante 15: atuante no Ensino Fundamental e Médio, em escola privada na área urbana).

Vieira e Ricci (2020) acreditam que este período pandêmico provocou muitas reflexões - ou lições, ainda que iniciais acerca do que precisará ser mudado na escola "pós-pandemia”, sendo uma delas a questão curricular. Para eles, "quem apenas segue currículos, sem estabelecer relações diretas com seu público e com a realidade que o cerca, não entendeu o mandato educacional" (Vieira \& Ricci 2020 p. 3).

\section{Considerações Finais}

O Brasil apresenta diversidade de realidades educacionais, sociais e econômicas e este é um grande desafio para a Educação, mesmo em períodos não emergenciais. Buscando contribuir com os estudos que mapeiam as práticas pedagógicas neste período de pandemia provocada pela Covid-19, esta pesquisa contou com a participação de professores atuantes em instituições de ensino de várias regiões brasileiras e apresentou dados relevantes para entendermos as possibilidades e limitações do ensino remoto emergencial. 
Diferentes contextos de atuação foram contemplados nessa pesquisa, mas em muitos aspectos foram convergentes. $\mathrm{O}$ obstáculo do acesso aos recursos tecnológicos e à internet pelos alunos e professores, a falta de autonomia da aprendizagem dos alunos e o comprometimento da saúde psíquica e emocional dos alunos, pais e professores na pandemia foram pontos destacados por grande número de participantes.

Embora grande parte dos participantes tenha dito não terem dificuldade para a utilização de ferramentas tecnológicas, fica evidente que não foi possível oferecer aos professores uma formação para a docência em um modelo não presencial de ensino; apesar de eles terem equipamentos eletrônicos em casa, estes eram utilizados em outras tarefas (ainda que ligadas ao ensino), mas não para a preparação de aulas, gravação e edição de vídeos, acesso a softwares e a plataformas que agora se tornariam a sua sala de aula virtual onde os materiais produzidos deveriam ser disponibilizados, e os encontros síncronos ali aconteceriam.

$\mathrm{O}$ estudo apontou que mesmo para os alunos que conseguem ter acesso ao ensino remoto, o quanto têm aprendido ainda é uma incógnita. A pouca interação, participação e retorno das atividades revelados por quase metade (48,37\%) dos participantes indicam a sua preocupação se, de fato, o processo de ensino e aprendizagem está sendo efetivo. Diversos fatores relacionados ao aluno, família, recursos, infraestrutura para o estudo, instituição e ao próprio professor, em menor ou maior grau, têm influenciado a participação ativa e a interação entre alunos e professores no ensino remoto emergencial.

O período é de grande instabilidade e as instituições de ensino e professores que ainda não haviam realizado atividades em agosto de 2020 poderiam estar em fase de preparação para o ensino remoto. No entanto, algumas medidas adotadas pelas instituições revelam o desrespeito e a desvalorização com os profissionais da educação, como a imposição da exposição da imagem, excesso de atividades e imposição de ações invasivas à privacidade do educador que interferem diretamente na sua vida pessoal. Tudo isso pode (e tem) culminar em quadros de ansiedade, estresse e depressão nos profissionais da educação, especialmente nos professores.

Mesmo diante das incertezas, desafios e angústias desse momento da pandemia, muitos profissionais da educação consideraram ter aprendido importantes lições que refletirão na sua vida profissional e pessoal, como habilidade para o uso das ferramentas digitais e um maior altruísmo entre estes indivíduos.

\section{Referências}

Bacich, L. (2020). Ensino híbrido: muito mais do que unir aulas presenciais e remotas. Inovação na Educação. http://lilianbacich.com/2020/06/06/ensinohibrido-muito-mais-do-que-unir-aulas-presenciais-e-remotas/.

Barbosa A. M., Viegas, M. A. S. \& Batista, R. L. N. F. F. (2020). Aulas presenciais em tempos de pandemia: relatos de experiências de professores do nível superior sobre as aulas remotas. Revista Augustus, v.25, n. 51, p. 255-280.

Bardin, L. (1977). Análise de conteúdo. Edições 70.

Barros, P. M. de, Coelho, B., Camargos, H., Lélis, I. C. \& Kloster Júnior, M. (2020). Didática de transição: a formação docente e o ensino remoto emergencial em tempos de pandemia. Revista Dito Efeito, 11(19), 48-57.

Brasil, Ministério da Educação. (2020). Dispõe sobre a substituição das aulas presenciais por aulas em meios digitais enquanto durar a situação de pandemia do Novo Coronavírus - Covid-19. Portaria no 343, de 17 de março de 2020.

http://www.planalto.gov.br/ccivil_03/Portaria/PRT/Portaria\%20n\%C2\%BA\%20343-20-mec.htm.

Catanante, F., Dantas, I. L. de S. \& Campos, R. C. (2020). Aulas on-line durante a pandemia: condições de acesso asseguram a participação do aluno?. Revista Educação Científica, 4(8), 977-988.

Cavalcante, V., Komatsu, B. K. \& Menezes Filho, N. (2020). Desigualdades Educacionais durante a Pandemia. Instituto de Ensino e Pesquisa (Insper), Policy Paper, $n^{\circ} 51$.

Coletivo de Estudos em Marxismo e Educação - COLEMARX. (2020). Em defesa da educação pública comprometida com a igualdade social: Porque os trabalhadores não devem aceitar o trabalho remoto. http://colemarx.educacao.ufrj.br/wp-content/uploads/2020/09/Colemarx-texto-cri\%CC\%81tico-EaD2.pdf.

Costa, B. R. L. (2018). Bola de neve virtual: O uso das redes sociais virtuais no processo de coleta de dados de uma pesquisa científica. Revista Interdisciplinar de Gestão Social, 7(1), 15-37. 
Research, Society and Development, v. 10, n. 15, e157101522485, 2021

(CC BY 4.0) | ISSN 2525-3409 | DOI: http://dx.doi.org/10.33448/rsd-v10i15.22485

Diehl, A. A. (2006). Pesquisa em ciências sociais aplicadas: métodos e técnicas. Pearson.

Esteve, J. M. (1999). O mal-estar docente: a sala de aula e a saúde dos professores. EDUSC.

Fundação Carlos Chagas. (2020). Educação escolar em tempos de pandemia. Informe $\mathrm{n}^{\circ}$ 1. 2020. http://www.fcc.org.br/fcc/educacao-pesquisa/educacaoescolar-em-tempos-de-pandemia-informe-n-1.

Grupo de Estudos sobre Política Educacional e Trabalho Docente (GESTRADO/UFMG). (2020). Trabalho docente em tempos de pandemia- Relatório Técnico. http://www.gestrado.net.br/pesquisas/.

Hashizume, C. M. (2020). Saúde mental docente e a Covid-19: Desafios para o cuidado ao cuidador. Grupo de Pesquisa Educação em Direitos Humanos UFABC. Contemporartes: Revista Semanal de Difusão Cultural, 11, 1-4.

Hodges, C., Trust,T., Moore, , Bond, A. \& Lockee, B.(2020). As diferenças entre o aprendizado online e o ensino remoto de emergência. Revista da escola, professor, educação e tecnologia, 2, 1-12.

Kubota, L. C. (2020). A infraestrutura sanitária e tecnológica das escolas e a retomada das aulas em tempos de Covid-19. http://www.ipea.gov.br/portal/images/stories/PDFs/nota_tecnica/200715_nt_diset_n_70_web.pdf.

Moran, J. (2017). Metodologias ativas e modelos híbridos na educação. In: Yaegashi, S., Bianchini, L. G. B., Oliveira Júnior, I. B. de, Santos, A. R. dos, Silva, S. F. da (Orgs), Novas Tecnologias Digitais: Reflexões sobre mediação, aprendizagem e desenvolvimento (p.23-35). Curitiba: Editora CRV. http://www2.eca.usp.br/moran/wp-content/uploads/2018/03/Metodologias_Ativas.pdf.

Organização das Nações Unidas para a Educação, a Ciência e a Cultura- UNESCO. (2020). Situação da educação no Brasil (por região/estado). https://pt.unesco.org/fieldoffice/brasilia/covid-19-education-Brasil.

Pereira, H. P., Santos, F. V. \& Manenti, M. A. (2020). Saúde Mental de Docentes em Tempos de Pandemia: os impactos das atividades remotas. Boletim de Conjuntura (Boca), 3(9), 26-32.

Ruschel, G. E. S., Trevisan, M. B. \& Pereira, J. F. (2020). Ensino remoto no contexto de uma instituição privada. Observatório Socioeconômico da COVID19. Santa Maria: UFSM. http://www.ufsm.br/app/uploads/sites/820/2020/10/Textos-para-Discussao-18-Ensino-Remoto-em-uma-instituicao-particular.pdf.

Sampieri, R. H., Collado, C. F.\& Lucio, P. B. (2006). Metodologia de Pesquisa. McGraw-Hill Interamericana do Brasil Ltda.

Valle, P. D. \& Marcom, J. L. R. (2020). Desafios da prática pedagógica e as competências para ensinar em tempos de pandemia. In: Palú, J., Schütz, J. A., Mayer, L. (Orgs), Desafios da educação em tempos de pandemia (1ed., v. 1, pp. 139-152). Editora Ilustração.

Vieira L. \& Ricci, M. C. K. (2020). A educação em tempos de pandemia: soluções emergenciais pelo mundo. Observatório do Ensino Médio em Santa Catarina: OEMESC/ UNESC.

http://www.udesc.br/arquivos/udesc/id_cpmenu/7432/EDITORIAL_DE_ABRIL_Let_cia_Vieira_e_Maike_Ricc i_final_15882101662453_7432.pdf. 